Research Article

\title{
Exercise Training Induced Cardioprotection with Moderate Hyperglycemia versus Sedentary Intensive Glycemic Control in Type 1 Diabetic Rats
}

\author{
Matthew W. McDonald, ${ }^{1}$ Michelle S. Dotzert, ${ }^{1}$ Mao Jiang, ${ }^{1}$ Michael R. Murray, ${ }^{1}$ \\ Earl G. Noble $\left(\mathbb{i},{ }^{1,2}\right.$ and C. W. James Melling $\mathbb{1}^{1}$ \\ ${ }^{1}$ Exercise Biochemistry Laboratory, School of Kinesiology, Western University, London, ON, Canada \\ ${ }^{2}$ Lawson Health Research Institute, London, ON, Canada \\ Correspondence should be addressed to C. W. James Melling; jmelling@uwo.ca
}

Received 7 March 2018; Accepted 16 May 2018; Published 5 July 2018

Academic Editor: Markus Wallner

Copyright (c) 2018 Matthew W. McDonald et al. This is an open access article distributed under the Creative Commons Attribution License, which permits unrestricted use, distribution, and reproduction in any medium, provided the original work is properly cited.

\begin{abstract}
Intensive insulin therapy (IIT; $4-7 \mathrm{mmol} / \mathrm{L}$ ) is the preferred treatment for type 1 diabetes mellitus (T1DM) patients to reduce the risk of cardiovascular disease (CVD). However, this treatment strategy has been questioned as it is accompanied with a sedentary lifestyle leading to weight gain and insulin resistance. T1DM patients who partake in high-intensity aerobic training $\left(\mathrm{AT}_{\text {high }}\right)$ to reduce $\mathrm{CVD}$ often utilize conventional insulin therapy (CIT; $9-15 \mathrm{mmol} / \mathrm{L}$ ) to offset the risk of hypoglycemia. Moreover, exercise modalities incorporating resistance training (RT) have been shown to further reduce this risk. The purpose of this investigation was twofold: (1) to determine if CIT paired with $\mathrm{AT}_{\text {high }}$ results in larger cardioprotection from an ischemia-reperfusion (I-R) injury than IIT and (2) to establish if the integration of RT with $\mathrm{AT}_{\text {high }}$ (ART) results in similar cardioprotection as $\mathrm{AT}_{\text {high }}$. Diabetic (D) male Sprague-Dawley rats were divided into D-IIT $(n=12), \mathrm{D}$-CIT $(n=12), \mathrm{D}$ - $\mathrm{AT}_{\text {high }}$ $(n=8)$, D-RT $(n=8)$, and D-ART $(n=8)$. T1DM was induced with streptozotocin, and blood glucose was adjusted with

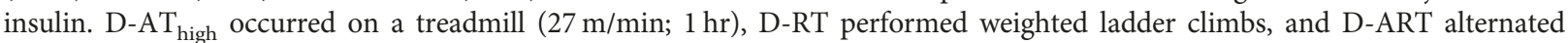
daily between $\mathrm{AT}_{\text {high }}$ and RT. Exercise occurred 5 days/wk for 12 wks. This investigation demonstrates that cardioprotection following an I-R injury was similar between D-AThigh and D-IIT. This cardioprotection is not exercise-specific, and each provides unique advantages. $\mathrm{D}-\mathrm{AT}_{\text {high }}$ leads to improved glycemia while insulin sensitivity was enhanced following resistance exercises. Thus, exercise is an effective means to elicit cardioprotection in T1DM. However, in addition to glycemia, other factors should be considered when tailoring an exercise program for T1DM patients.
\end{abstract}

\section{Introduction}

Individuals with type 1 diabetes mellitus (T1DM) exhibit a heightened risk for cardiovascular disease (CVD) not entirely accounted for by traditional risk factors (hyperglycemia, obesity, hypertension, dyslipidemia, and smoking) [1]. To date, the most characterized strategies to limit CVD development have been intensive insulin therapy (IIT) [2] and regular exercise [3-5]. However, both IIT and exercise potentiate the risk of hypoglycemia, especially when attempted collectively $[2,6]$. To counteract hypoglycemia risk, individuals with T1DM often intentionally elevate their blood glucose concentrations prior to exercise through changes in insulin dosing and/or carbohydrate ingestion [7]. As such, individuals with T1DM who are more physically active typically prescribe to a more conventional insulin therapy (CIT) and have higher HbAlc values with reduced focus on glycemic control [8].

Additional work is needed to better evaluate the cardiovascular benefits and risks associated with regular exercise in physically active individuals with T1DM that often prescribe to less stringent glycemic control, since elevations in glycemia $\left(\mathrm{HbA}_{1 \mathrm{c}}\right)$ are known to increase the risk of cardiovascular complications [2]. Our group has demonstrated that 
the combination of less stringent blood glucose control and high-intensity aerobic exercise training $\left(\mathrm{AT}_{\text {high }}\right)$ in experimental T1DM rats not only decreases the risk of exercise-induced hypoglycemia [4] but also has numerous cardiovascular benefits such as increased recovery from an ischemic insult [4], reduction in cardiovascular autonomic dysfunction [9], improvement in systolic and diastolic heart function [5], and improved vascular reactivity [10, 11]. It is unknown how these cardiovascular benefits would compare to stringent blood glucose control alone (i.e., IIT), the predominant treatment option for individuals with T1DM $[2,12]$. This is a significant question that needs to be answered since IIT is associated with cardiovascular risk factors such as increased sedentary behaviour, weight gain, and insulin resistance $[8,13,14]$.

Additionally, it has been established both experimentally [15] and clinically [16] that poor glycemic control leads to hepatic glycogen deficiencies. Restoration of hepatic glycogen content could represent a mechanism for combatting hypoglycemia, as hepatic glycogen is the predominant source of blood glucose during exercise [17] and insulin overcorrection [18]. Our laboratory has recently shown that ten weeks of $\mathrm{AT}_{\text {high }}$ fails to normalize hepatic glycogen in T1DM rats despite significantly elevated levels of hepatic glycogenic storage enzymes [15]. In contrast, resistance training (RT) has been shown to increase hepatic glycogen content in rats [19], while also alleviating the risk of exercise-induced hypoglycemia in T1DM $[4,20]$. While still allowing for the cardiovascular benefits associated with regular aerobic exercise, the integration of RT with aerobic exercise may allow individuals with T1DM to exercise safely by reducing the risk of hypoglycemia development. Indeed, the Canadian Diabetes Association recommends that RT be incorporated into aerobic exercise regimes at least twice a week [21].

The objective of the present study was to examine whether moderate blood glucose control and $\mathrm{AT}_{\text {high }}$ result in greater levels of cardioprotection than more stringent blood glucose control. Secondly, it was determined whether combining $\mathrm{RT}$ with $\mathrm{AT}_{\text {high }}$ resulted in similar cardioprotection and less exercise-induced blood glucose fluctuations. Additionally, the potential relationship between glycemic status and cardioprotection was explored.

\section{Methods}

This study was approved by the Research Ethics Board of the University of Western Ontario which is in compliance with the guidelines of the Canadian Council on Animal Care. Eight-week-old male Sprague-Dawley rats were obtained from Charles River Laboratories, provided standard rat chow ad libitum, and housed in pairs at a standard temperature and humidity $\left(21.5^{\circ} \mathrm{C}\right.$ and $50 \%$ humidity).

2.1. Experimental Protocol. Sprague-Dawley rats were randomly divided into one of five diabetic groups (D): conventional insulin therapy (D-CIT; $n=12$ ), intensive insulin therapy (D-IIT; $n=12)$, high-intensity aerobic exercise training $\left(\mathrm{D}-\mathrm{AT}_{\text {high }} ; n=8\right)$, resistance exercise training (D-RT; $n=8$ ), and combination aerobic/resistance exercise training
(D-ART; $n=8$ ). During experimental week one, T1DM was induced after five consecutive daily injections of streptozotocin (Sigma-Aldrich; $20 \mathrm{mg} / \mathrm{kg}$; dissolved in $0.1 \mathrm{M}$ citrate buffer, $\mathrm{pH}$ 4.5) and T1DM was confirmed after two nonfasting blood glucose concentrations greater than $18 \mathrm{mmol} / \mathrm{L}$. After diabetes confirmation, subcutaneous insulin pellets (Linshin, Toronto, Canada) were implanted in the abdomen (experimental week two). Through insulin pellet adjustments, it was intended to maintain blood glucose concentrations in D-CIT, D-AT ${ }_{\text {high }}$, D-RT, and D-ART between 9 and $15 \mathrm{mmol} / \mathrm{L}$ and D-IIT between 4 and $9 \mathrm{mmol} / \mathrm{L}$. Exercise training occurred five times a week over a twelve-week period (experimental week 3 to 14 ). $\mathrm{D}-\mathrm{AT}_{\text {high }}$ rats exercised on a motorized treadmill at $27 \mathrm{~m} / \mathrm{min}$ (six percent grade) for one hour. Continuous running was encouraged by small blasts of compressed air at the rear of the treadmill. In D-RT rats, resistance training consisted of climbing a vertical ladder with weights secured to the proximal portion of the tail, as previously described [4]. Familiarization occurred the week prior to training (experimental week 2) and consisted of 10 climbs a day with varying weights attached $(5 \%, 15 \%, 20 \%$, and $35 \%$ of each rat's body mass). Regular resistance training sessions (experimental week 3 to 14) consisted of incremental increases in weight $(50 \%, 75 \%$, and $90 \%$ of maximal lifting capacity) followed by $100 \%$ of their maximal lifting capacity until exhaustion (unable to finish climb despite tactile stimulation to haunches). Maximum lifting capacity was calculated every fourth exercise session and was determined by sequentially adding 30 grams of weight to the rat's tail until exhaustion (starting at $75 \%$ of their body mass). In D-ART rats, exercise training consisted of alternating daily between the aerobic and resistance exercises.

2.2. Blood Analysis. Blood samples were taken over two consecutive days from the saphenous vein during the last week of exercise training (experimental week 14; pre/postexercise) to determine if antecedent $\mathrm{AT}_{\text {high }}$ or $\mathrm{RT}$ altered the blood glucose response to a subsequent exercise bout [22]. In DART, this measure was conducted at week 11 and week 12 of training (experimental week 13 and 14, resp.) to determine if performing $\mathrm{AT}_{\text {high }}$ (or RT) first had an effect on glucoregulation following a subsequent bout of RT (or $\mathrm{AT}_{\text {high }}$ ). Blood glucose concentrations were detected using a OneTouch Ultra 2 Blood Glucose Monitoring System (Lifescan Canada Ltd., Burnaby, BC, Canada) and OneTouch test strips (Lifescan Canada Ltd.). Epinephrine concentrations prior to and after exercise were determined via ELISA (Cusabio, catalog number CSB-E08678r). Fructosamine concentrations were determined using the procedure outlined by Oppel et al. [23]. Briefly, serum samples taken at the completion of the study were added to a carbonate buffer ( $\mathrm{pH} 10.8)$ containing $0.25 \mathrm{mM}$ nitroblue tetrazolium $(\mathrm{NBT})$ at $37^{\circ} \mathrm{C}$. Following a 20 -minute incubation at $37^{\circ} \mathrm{C}$, the reaction was read at $530 \mathrm{~nm}$ and compared to standards of 1-deoxy,1-morpholinofructose (DMF; Sigma-Aldrich) and albumin (40 g/L).

2.3. Langendorf Heart Preparation. Three days following the last exercise bout, all rats were anaesthetized with isoflurane and hearts were extracted and placed in cold 
TABLE 1: General animal characteristics at the completion of the study.

\begin{tabular}{lccccc}
\hline & D-CIT & D-IIT & D-AT $_{\text {high }}$ & D-RT & D-ART \\
\hline Body mass (g) & $567 \pm 20$ & $598 \pm 21^{3,4,5}$ & $510 \pm 15$ & $520 \pm 21$ & $534 \pm 19$ \\
Blood glucose conc. (mmol/L) & $15.0 \pm 1.2$ & $10.9 \pm 1.2^{1,3,5}$ & $15.6 \pm 0.5$ & $12.4 \pm 1.9^{5}$ & $16.7 \pm 1.4$ \\
Fructosamine conc. (mmol/L) & $3.0 \pm 0.5$ & $1.0 \pm 0.2^{1,5}$ & $1.3 \pm 0.3^{1,5}$ & $2.0 \pm 0.1$ & $2.6 \pm 0.7$ \\
Exogenous insulin (IU) & $27.3 \pm 5.4$ & $35.8 \pm 7.8$ & $19.0 \pm 7.7$ & $11.1 \pm 7.1^{2}$ & $4.1 \pm 2.0^{1,2}$ \\
Insulin resistance (AU) & $10,665 \pm 2078^{5}$ & $16,055 \pm 4558^{3,4,5}$ & $4722 \pm 1988$ & $1438 \pm 62^{3}$ & $1260 \pm 601^{3}$ \\
\hline
\end{tabular}

Data are means \pm SE. ${ }^{1}$ Different from D-CIT; ${ }^{2}$ different from D-IIT; ${ }^{3}$ different from D-AT ${ }_{\text {high }} ;{ }^{4}$ different from D-RT; ${ }^{5}$ different from D-ART.

Krebs-Henseleit buffer (KHB; $120 \mathrm{mM} \mathrm{NaCl}, 4.63 \mathrm{mM} \mathrm{KCl}$, $1.17 \mathrm{mM} \mathrm{KH}_{2} \mathrm{PO}_{4}, 1.25 \mathrm{mM} \mathrm{CaCl}_{2}, 1.2 \mathrm{mM} \mathrm{MgCl}_{2}, 20 \mathrm{mM}$ $\mathrm{NaHCO}_{3}$, and $8 \mathrm{mmol} / \mathrm{L}$ glucose). Hearts were rapidly cannulated for unpaced retrograde perfusion of $\mathrm{KHB}\left(37^{\circ} \mathrm{C}\right.$; gassed with $95 \% \mathrm{O}_{2}$ and $5 \% \mathrm{CO}_{2}$ ) at $15 \mathrm{~mL} / \mathrm{min}$. A small water-filled latex balloon was inserted through the mitral valve and into the left ventricle. Hearts were equilibrated to the preparation for 30 minutes (preischemia) followed by the termination of flow for 50 minutes. Subsequently, reperfusion occurred for a total of 30 minutes at $15 \mathrm{~m} / \mathrm{min}$. Left ventricle pressures (LVDP, left ventricle developed pressure; LVEDP, left ventricle end-diastolic pressure) were measured with a pressure transducer (Statham Gould P23ID), and the rate of pressure development $(+\mathrm{dp} / \mathrm{dt})$ and relaxation $(-\mathrm{dp} / \mathrm{dt})$ were obtained using a PowerLab 8/30 data acquisition system and analyzed by LabChart 7.0 Pro software (ADInstruments, Colorado Springs, Colorado, USA). Area under the curve (AUC) was determined for the pressure curves of each rat in the study in order to correlate measures to glycemic control and insulin resistance.

2.4. Glucose Tolerance Test. Intravenous glucose tolerance tests (IVGTT) were conducted following training (experimental week 14) after an 8-12-hour fast and consisted of a sterile injection $(1 \mathrm{~g} / \mathrm{kg})$ of dextrose solution ( $50 \%$ dextrose, $50 \% \mathrm{ddH}_{2} \mathrm{O}$ ) into the lateral tail vein. Blood glucose concentrations were measured at $5,10,20,30$, and 40 minutes postinjection, and area under the curves (AUC) were determined for each individual rat. Prior to the IVGTT, blood samples were taken from the saphenous vein and exogenous insulin concentrations were measured via ELISA (Alpco, Salem, $\mathrm{NH}$ : catalog number 80-INSHU-E01.1). The measure of insulin resistance was considered the AUC of the IVGTT multiplied by exogenous insulin concentration. We have previously reported that when using this T1DM model, sedentary rats can become insulin resistant and require substantial more exogenous insulin in order to maintain the desired blood glucose concentrations $[15,24]$. Accordingly, when determining the insulin resistance measure, the amount of circulating insulin present in the rat during the IVGTT was factored into the calculation.

2.5. Western Blotting. Liver (extracted during sacrifice at end of study) and left ventricles were homogenized in buffer $(100 \mathrm{mM} \mathrm{NaCl}, 50 \mathrm{mM}$ Tris base, $0.1 \mathrm{mM}$ EDTA, and 0.1 EGTA, pH 7.5) using a polytron, and total protein concentrations were determined by the Bradford protein assay. Homogenates ( $40-80 \mu \mathrm{g}$ of protein) were mixed with equal volumes of sample buffer $(0.125 \mathrm{M}$ Tris, $20 \%$ glycerol, $4 \%$ SDS, $10 \% \beta$-mercaptoethanol, $0.015 \%$ bromophenol blue, $\mathrm{pH} \sim 6.8$ ), separated by SDS-PAGE (4\% stacking, $10 \%$ separating) and transferred to nitrocellulose membranes. Membranes were blocked in 5\% nonfat dairy milk in TTBS ( $10 \mathrm{mM}$ Tris, $100 \mathrm{mM} \mathrm{NaCl}$, and $0.1 \%$ Tween-20, pH 7.5) for 1 hour and incubated overnight at $4{ }^{\circ} \mathrm{C}$ with primary antibodies (Cell Signaling: Hsp70 1:4000, glycogen synthase $1: 1000$; Abcam: glycogen phosphorylase $1: 2000$, SERCA2 1:1000; Santa Cruz: glucose-6-phosphotase 1:200) diluted in TTBS with $2 \%$ nonfat dairy milk. Following washes in TTBS, membranes were exposed to corresponding secondary antibodies (IgG-HRP conjugated, Bio-Rad) in TTBS with $2 \%$ nonfat dairy milk for 1 hour at room temperature. After successive washes in TTBS, protein bands were visualized with a luminol-based chemiluminescent substrate (Western C Enhanced Chemiluminescent Kit; Bio-Rad), imaged with the Chemidoc XRS System (Bio-rad), and analyzed with Quantity One Software (Bio-Rad). Optical densities were normalized to a consistent non-T1DM control sample and subsequently $\beta$-actin.

2.6. Statistical Analysis. Body mass, blood glucose, fructosamine, exogenous insulin, insulin resistance, and Western blot data were compared using a one-way analysis of variance (ANOVA). Langendorf measures were compared using a two-way repeated measure ANOVA. Blood glucose concentrations and epinephrine concentrations in response to exercise, and over consecutive days, were compared using a two-way repeated measures ANOVA. When a significant difference was found, a least squares difference post hoc test was performed and significance was set at $p<0.05$. Relationships between left ventricular mechanical performance and fructosamine or insulin resistance were determined via Pearson correlation. All data are presented as a mean \pm standard error. All statistical analyses were completed using GraphPad Prism 6.

\section{Results}

3.1. Animal Characteristics. Blood glucose concentrations were lower in D-IIT compared to D-CIT $(p=0.03)$, D$\mathrm{AT}_{\text {high }}(p=0.02)$, and D-ART $(p=0.007)$, and lower in D-RT compared to D-ART ( $p=0.04)$ (Table 1$)$. Body mass was higher in D-IIT compared to D-AT $\mathrm{Aigh}(p=0.003)$, DRT $(p=0.01)$, and D-ART $(p<0.04)$. Fructosamine concentrations were lower in D-IIT compared to D-CIT $(p<0.001)$ and D-ART $(p=0.01)$. Further, fructosamine concentrations 


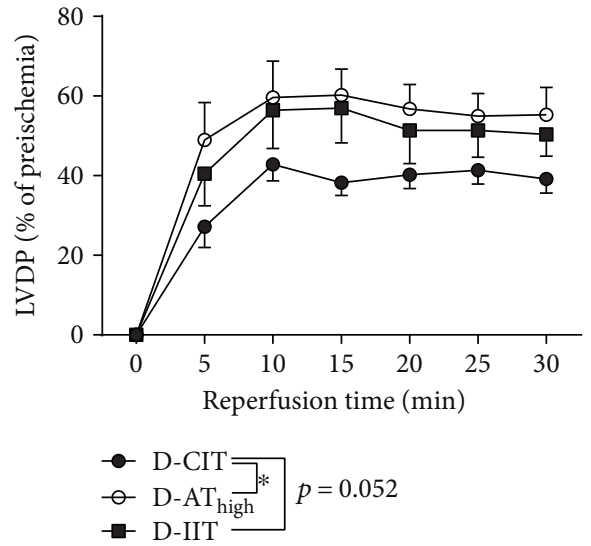

(a)

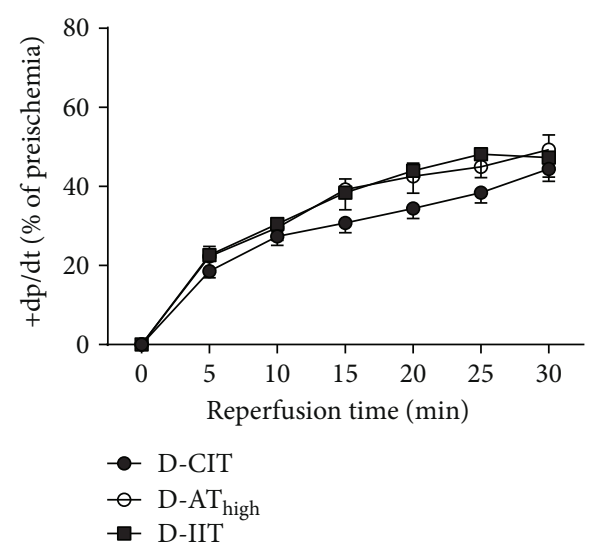

(c)

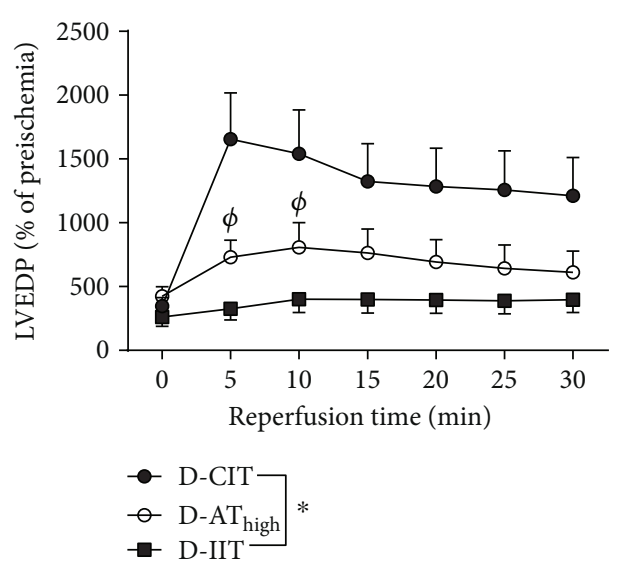

(b)

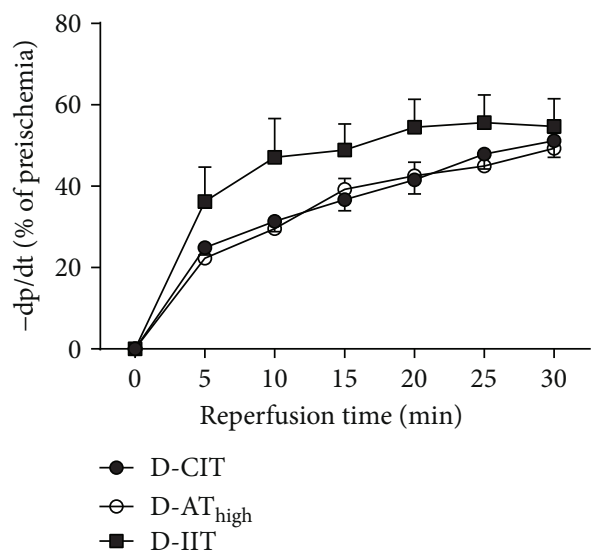

(d)

FIGURE 1: Left ventricle mechanical performance during ischemia-reperfusion. The data are presented in time course format. LVDP (a), LVEDP (b), $+\mathrm{dP} / \mathrm{dt}(\mathrm{c}),-\mathrm{dP} / \mathrm{dt}(\mathrm{d}) .{ }^{*}$ Significant main effect $(p<0.05) ;(\varphi)$ different from D-CIT $(p<0.05)$. Data are presented as a mean \pm SE.

were lower in $\mathrm{D}-\mathrm{AT}_{\text {high }}$ compared to D-CIT $(p=0.003)$ and D-ART $(p=0.04)$. Exogenous insulin concentrations were lower in D-RT compared to D-IIT $(p=0.01)$, and lower in D-ART compared to D-CIT $(p=0.02)$ and D-IIT $(p<0.001)$. The insulin resistance measure was higher in D-IIT compared to $\mathrm{D}-\mathrm{AT}_{\text {high }}(p=0.02), \mathrm{D}-\mathrm{RT}(p=0.008)$, and D-ART $(p=0.003)$. Further, D-CIT displayed higher insulin resistance compared to D-ART $(p=0.04)$.

3.2. Left Ventricular Mechanical Performance. For the first objective of the study, we compared left ventricular mechanical performance following ischemia in D-CIT, D- $\mathrm{AT}_{\text {high }}$, and D-IIT. There was a significant increase in LVDP in D$\mathrm{AT}_{\text {high }}$ compared to D-CIT (Figure $1(\mathrm{a}) ; p=0.03$ ). No difference in LVDP was observed between $\mathrm{D}-\mathrm{AT}_{\text {high }}$ and D-IIT $(p=0.5)$, and LVDP between D-CIT and D-IIT did not reach significance $(p=0.052)$. LVEDP was lower in D-IIT compared to D-CIT (Figure 4.1B; $p=0.004$ ), while D-AT high was lower than D-CIT at $5(p<0.0001)$ and 10 minutes $(p=0.03)$ during reperfusion. There was no difference in $+\mathrm{dp} / \mathrm{dt}(p=0.4)$ or $-\mathrm{dp} / \mathrm{dt}(p=0.2)$ across any of the groups (Figures 1(c) and 1(d)).

For the second objective of the study, we compared left ventricle mechanical performance following ischemia in $\mathrm{D}-\mathrm{AT}_{\text {high }}, \mathrm{D}-\mathrm{RT}$, and D-ART. There were no differences

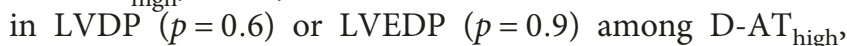
D-RT, and D-ART (Figures 2(a) and 2(b)). Compared to $\mathrm{D}-\mathrm{AT}_{\text {high }}, \mathrm{D}-\mathrm{ART}$ had a higher $+\mathrm{dp} / \mathrm{dt}$ at $25(p=0.01)$ and 30 minutes $(p=0.005)$ during reperfusion (Figure 2(c)). Compared to D-RT, D-ART had a higher $+\mathrm{dp} / \mathrm{dt}$ at $25(p=$ $0.009)$ and 30 minutes $(p=0.002)$ during reperfusion. $D$ $\mathrm{AT}_{\text {high }}$ had a slower $-\mathrm{dp} / \mathrm{dt}$ than $\mathrm{D}-\mathrm{RT}$ at $20(p=0.04)$, $25(p=0.001)$, and 30 minutes $(p<0.0001)$ (Figure $2(d))$. Further, D-AT ${ }_{\text {high }}$ had a slower $-\mathrm{dp} / \mathrm{dt}$ than D-ART at 20 $(p=0.04), 25(p=0.002)$, and 30 minutes $(p<0.0001)$.

3.3. Correlations of Left Ventricular Mechanical Performance. There was a significant correlation between the AUC of LVDP and fructosamine concentration (Table $2 ; p=0.01 ; r=-0.4$ ), while no correlation was evident between the AUC of LVEDP $(p=0.8),+\mathrm{dp} / \mathrm{dt}(p=0.7),-\mathrm{dp} / \mathrm{dt}(p=0.8)$, and fructosamine concentration. There was a significant correlation between the AUC of $+\mathrm{dp} / \mathrm{dt}$ and insulin resistance $(p=0.03 ; r=-0.4)$, but no correlation between insulin resistance and the AUC of $\operatorname{LVDP}(p=0.7), \operatorname{LVEDP}(p=0.65)$, or $-\mathrm{dp} / \mathrm{dt}(p=0.5)$.

3.4. Molecular Analysis. An elevation in left ventricle Hsp70 content was evident in $\mathrm{D}$ - $\mathrm{AT}_{\text {high }}$ compared to both $\mathrm{D}$-CIT 

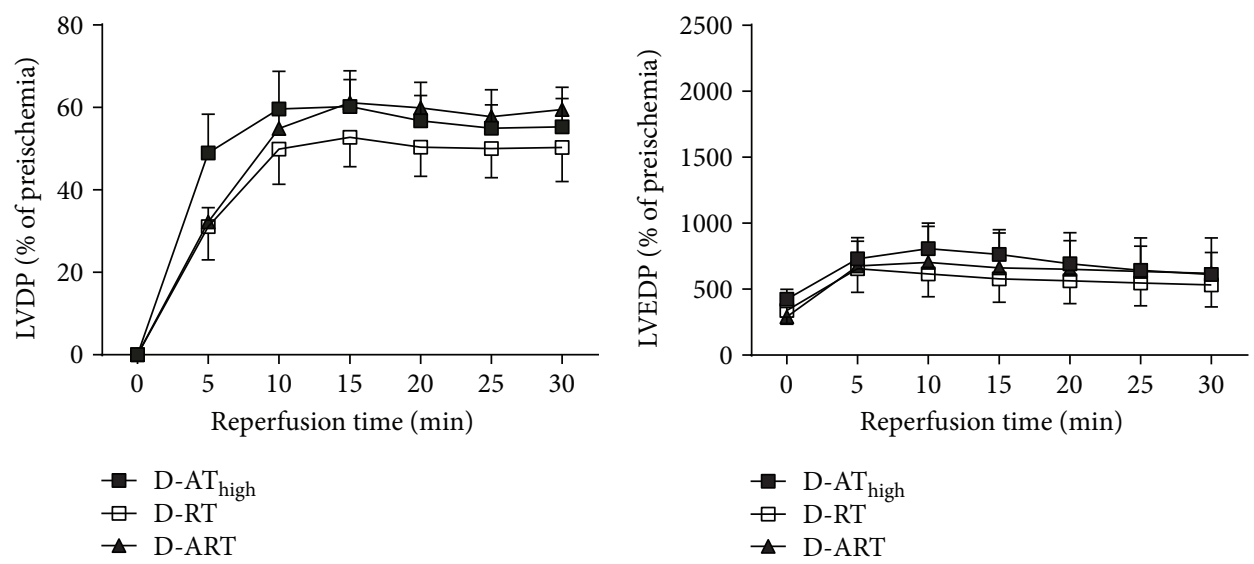

(a)

(b)

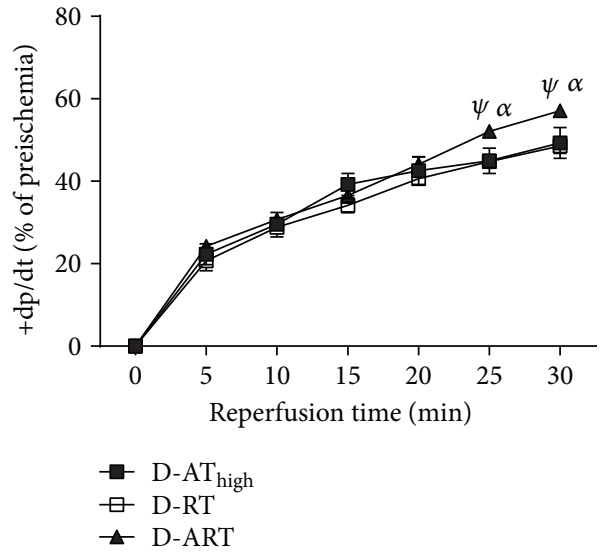

(c)

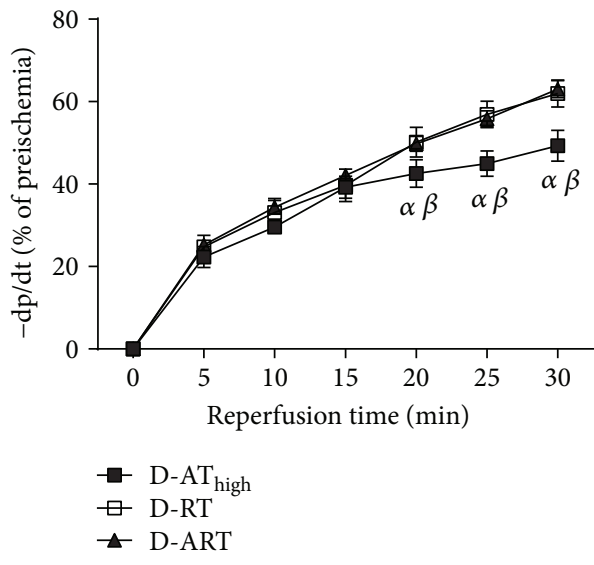

(d)

FIGURE 2: Left ventricle mechanical performance during ischemia-reperfusion and following different modalities of exercise training. The data are presented in time course format. LVDP (a), LVEDP (b), $+\mathrm{dP} / \mathrm{dt}(\mathrm{c}),-\mathrm{dP} / \mathrm{dt}(\mathrm{d}) . \psi$ : different from $\mathrm{D}-\mathrm{AT}_{\text {high }}(p<0.05) ; \alpha$ : different from D-RT $(p<0.05) ; \beta$ : different from D-ART $(p<0.05)$. Data are presented as a mean \pm SE.

TABLE 2: Correlation of left ventricle mechanical performance on glycemia and insulin resistance.

\begin{tabular}{lcccc}
\hline & \multicolumn{2}{c}{$\begin{array}{c}\text { Versus } \\
\text { fructosamine } \\
(\mathrm{mmol} / \mathrm{L})\end{array}$} & \multicolumn{2}{c}{$\begin{array}{c}\text { Versus insulin } \\
\text { resistance }(\mathrm{AU})\end{array}$} \\
& $p$ value & $r$ & $p$ value & $r$ \\
\hline LVDP (AUC) & $0.01^{*}$ & -0.4 & 0.7 & - \\
LVEDP (AUC) & 0.8 & - & 0.7 & - \\
$+\mathrm{dp} / \mathrm{dt}$ (AUC) & 0.7 & - & $0.03^{*}$ & -0.4 \\
$-\mathrm{dp} / \mathrm{dt}$ (AUC) & 0.8 & - & 0.5 & - \\
\hline
\end{tabular}

${ }^{*}$ Significant $(p<0.05)$.

$(p=0.003)$ and D-IIT $(p=0.009)$ (Figure 3(a)), while no differences were evident in SERCA2 among D-CIT, D-IIT, and $\mathrm{D}-\mathrm{AT}_{\text {high }}$ (Figure 3(b); $p=0.8$ ). Differences existed between exercise regimes in that $\mathrm{D}-\mathrm{AT}_{\text {high }}$ resulted in higher left ventricle Hsp70 compared to D-RT $(p=0.02)$, but did not differ significantly from D-ART (Figure $3(\mathrm{a}) ; p=0.1$ ). No differences in SERCA2 expression were evident among exercise regimes (Figure 4.3B; $p=0.4$ ).
3.5. Hepatic Glycogen Content and Regulatory Enzymes. Hepatic glycogen content was higher in D-CIT compared to $\mathrm{D}-\mathrm{AT}_{\text {high }}(p=0.05)$, D-RT $(p=0.01)$, and D-ART $(p=$ $0.004)$ (Figure 4(a)). Hepatic glycogen was also higher in D-IIT compared to D-AT $\mathrm{Aigh}(p=0.04)$, D-RT $(p=0.01)$, and D-ART $(p=0.004)$. No differences in glycogen synthase $(p=0.9)$, glycogen phosphorylase $(p=0.9)$, and glycogen-6phosphatase $(p=0.7)$ were apparent between experimental groups (Figures $4(\mathrm{~b})-4(\mathrm{~d})$ ).

3.6. Exercise-Mediated Changes in Blood Glucose. Significant declines in blood glucose concentrations following exercise were apparent in $\mathrm{D}-\mathrm{AT}_{\text {high }}$ at day 1 and day 2 of exercise (week 12 of training; Table $3 ; p<0.0001$ ). No change in blood glucose concentrations was apparent following RT at day 1 or day 2 (week 12 of training; $p=0.5$ ). In D-ART, significant declines in blood glucose concentrations were apparent only on $\mathrm{AT}_{\text {high }}$ days at both week $11(p=0.0003)$ and week $12(p<0.0001)$ of training. In $\mathrm{D}-\mathrm{AT}_{\text {high }}$, no change in epinephrine concentrations was evident from pre to postexercise (week 12 of training; $p=0.4$; Table 4 ), and epinephrine concentrations were similar between day 1 and day 2 (week 12 of training; $p=0.2$ ). In D-RT, no change in 


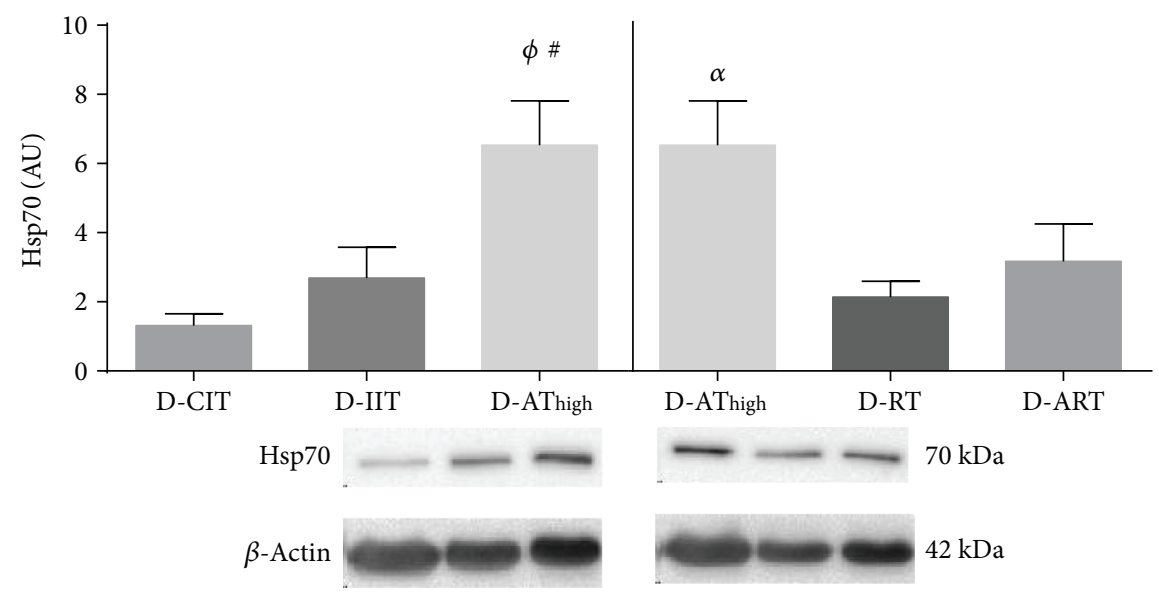

(a)

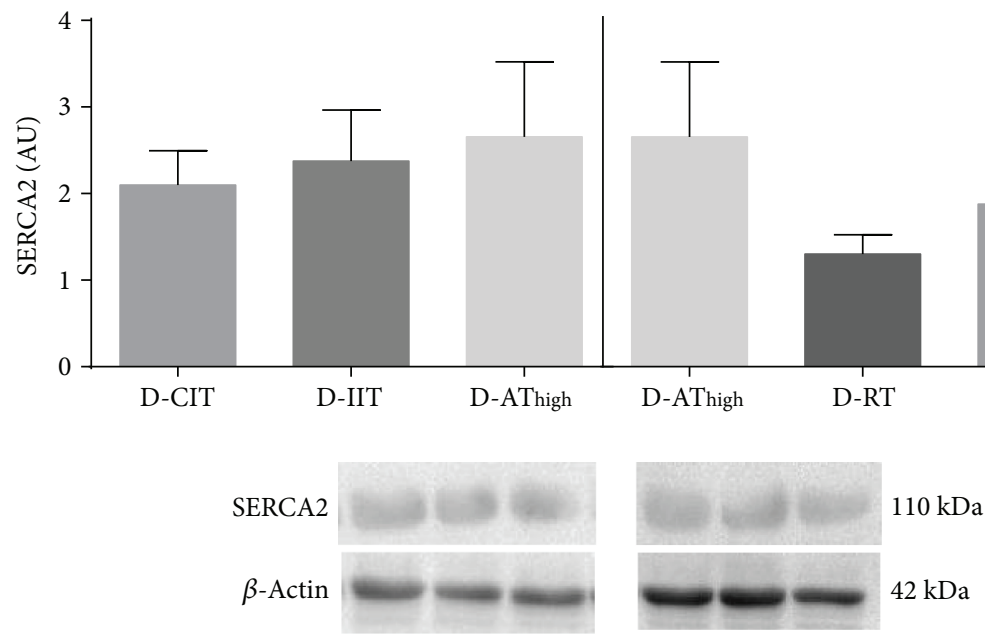

(b)

Figure 3: Left ventricle Hsp70 (a) and SERCA2 (b) protein content. $\phi$ : different from D-CIT; \#: different from D-IIT; $\alpha$ : different from D-RT. Significance $p<0.05$. Data are presented as a mean \pm SE.

epinephrine concentrations was evident from pre to postexercise (week 12 of training; $p=0.7$ ); however, epinephrine concentrations were lower overall on day 2 compared to day 1 (week 12 of training; $p=0.02$ ). In $\mathrm{D}$-ART, when RT occurred the day before $\mathrm{AT}_{\text {high }}$ (week 11 of training), epinephrine concentrations were reduced overall during $\mathrm{AT}_{\text {high }}(p=0.007)$. In D-ART, no change in epinephrine occurred from pre to postexercise at both week $11(p=0.5)$ and week $12(p=0.2)$ of training.

\section{Discussion}

Stringent management of blood glucose concentrations through intensive insulin therapy is the primary treatment strategy in order to limit the progression of CVD in patients with T1DM [2]. Indeed, D-IIT resulted in greater recovery from an I-R injury than D-CIT, supporting the deleterious effects of chronic hyperglycemia on the macrovasculature in individuals with T1DM $[12,25]$. In a previous study, we reported that six weeks of high-intensity aerobic exercise led to significant improvements in I-R functional recovery
[4]. Here, we demonstrate that this modality of exercise when combined with CIT can lead to comparable recovery from an I-R injury as IIT alone. It is important to note that while exercised animals were maintained in a chronic hyperglycemic state, $\mathrm{AT}_{\text {high }}$ exhibited similar serum fructosamine concentrations as IIT. It is likely that glycemic control played a significant role in contributing to the increased cardioprotection of IIT and $\mathrm{AT}_{\text {high }}$, since both exhibited similar serum fructosamine concentrations. Indeed, the negative correlation between serum fructosamine, indicative of glycemic control, and LVDP would support this finding.

While it is well-recognized that regular exercise can improve glycemic control (lowered $\mathrm{HbA}_{1 \mathrm{C}}$ ) in type 2 diabetes, results in T1DM have generally failed to show this glycemic benefit [3]. A number of factors may contribute to this lack of evidence in previous studies, including the predominant use of adolescent subjects, the use of questionnaires to estimate activity levels, or the increased food consumption that is typically associated with the initiation of an exercise program [3]. Although comparable to $\mathrm{HbA}_{1 \mathrm{c}}$, the measure of glycosylated hemoglobin, fructosamine is a measure of 


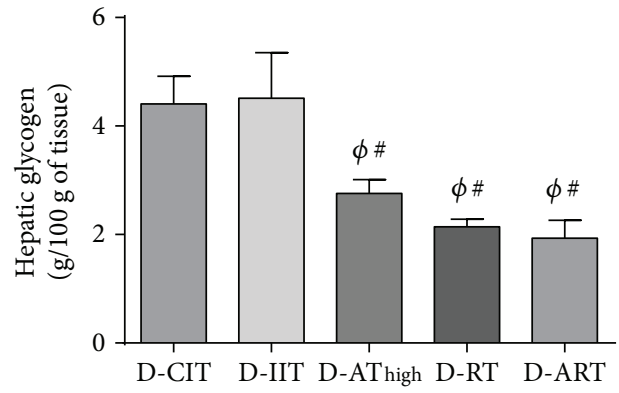

(a)

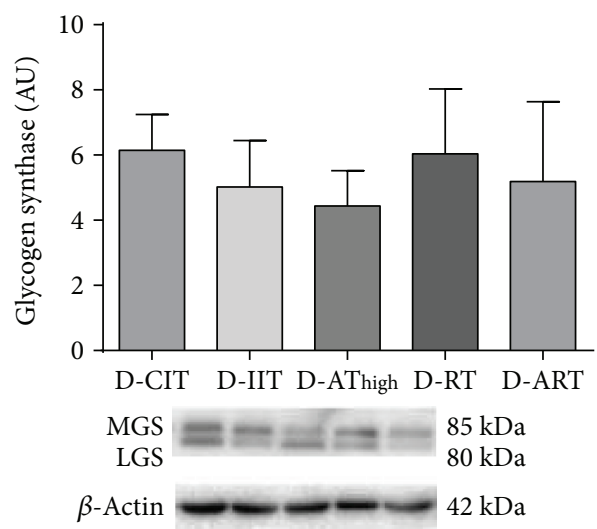

(c)

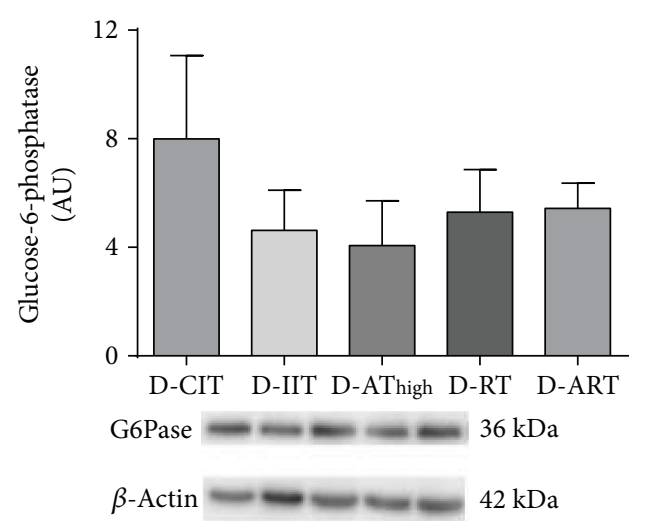

(b)

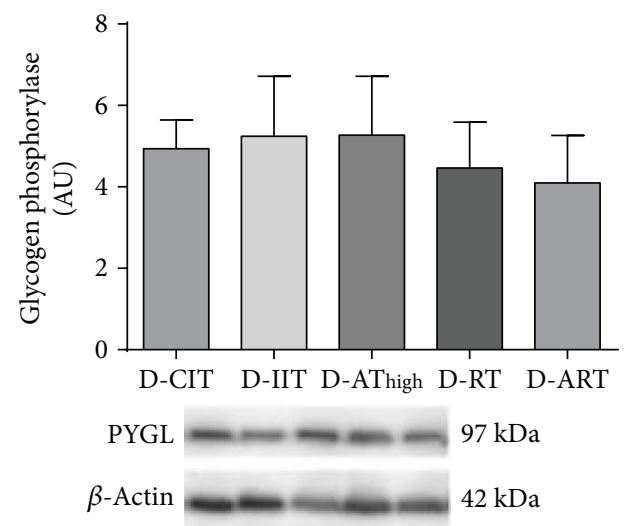

(d)

FIGURE 4: Hepatic glycogen content (a), glycogen-6-phosphatase (b), glycogen synthase (MGS: muscle glycogen synthase; LGS: liver glycogen synthase) (c), and glycogen phosphorylase (d). $\phi$ : different from D-CIT $(p<0.05)$; \#: different from D-IIT $(p<0.05)$. Data are presented as a mean \pm SE.

TABLE 3: Blood glucose concentrations in response to exercise at week 11 or week 12 of training.

\begin{tabular}{|c|c|c|c|c|}
\hline & \multicolumn{2}{|c|}{ Day 1} & \multicolumn{2}{|c|}{ Day 2} \\
\hline & Preexercise (mmol/L) & Postexercise $(\mathrm{mmol} / \mathrm{L})$ & Preexercise (mmol/L) & Postexercise $(\mathrm{mmol} / \mathrm{L})$ \\
\hline $\mathrm{D}-\mathrm{AT}_{\text {high }}$ & $15.0 \pm 0.4$ & $8.0 \pm 1.1^{*}$ & $14.6 \pm 0.5$ & $6.9 \pm 1.0^{*}$ \\
\hline D-RT & $12.2 \pm 1.6$ & $12.0 \pm 0.9$ & $13.6 \pm 2.2$ & $15.1 \pm 1.6$ \\
\hline D-ART (week 11; RT then $\mathrm{AT}_{\text {high }}$ ) & $14.9 \pm 1.6$ & $15.6 \pm 1.2$ & $15.4 \pm 1.7$ & $8.0 \pm 1.8^{*}$ \\
\hline D-ART (week 12; $\mathrm{AT}_{\text {high }}$ then RT) & $16.7 \pm 1.4$ & $8.8 \pm 1.4^{*}$ & $15.2 \pm 2.0$ & $15.6 \pm 1.2$ \\
\hline
\end{tabular}

Data are means \pm SE. ${ }^{*}$ Significantly lower than preexercise $(p<0.05)$.

TABLE 4: Epinephrine concentrations in response to exercise at week 11 or week 12 of training.

\begin{tabular}{|c|c|c|c|c|}
\hline & \multicolumn{2}{|c|}{ Day 1} & \multicolumn{2}{|c|}{ Day 2} \\
\hline & Preexercise $(\mathrm{pg} / \mathrm{mL})$ & Postexercise $(\mathrm{pg} / \mathrm{mL})$ & Preexercise $(\mathrm{pg} / \mathrm{mL})$ & Postexercise $(\mathrm{pg} / \mathrm{mL})$ \\
\hline $\mathrm{D}-\mathrm{AT}_{\text {high }}$ & $254.3 \pm 44.6$ & $93.1 \pm 24.9$ & $237.0 \pm 43.8$ & $298.0 \pm 109.1$ \\
\hline D-RT & $320.8 \pm 72.2$ & $238.3 \pm 58.2$ & $110.0 \pm 46.1^{*}$ & $136.3 \pm 66.3^{*}$ \\
\hline D-ART (week 11; RT then $\mathrm{AT}_{\text {high }}$ ) & $254.3 \pm 107.2$ & $150.8 \pm 98.0$ & $38.7 \pm 9.3^{*}$ & $57.8 \pm 15.1^{*}$ \\
\hline D-ART (week 12; $\mathrm{AT}_{\text {high }}$ then RT) & $331.0 \pm 169.8$ & $112.6 \pm 45.7$ & $202.2 \pm 33.0$ & $184.6 \pm 41.8$ \\
\hline
\end{tabular}

Data are means \pm SE. ${ }^{*}$ Significantly lower than day $1(p<0.05)$.

the amount of serum proteins that have undergone glycation and is thus a better marker for shorter-term glycemic control (approximately two weeks). While there is a shortage of evidence supporting increased glycemic control in T1DM following aerobic exercise [3], exercise intensity appears to play a significant role as to whether glycemic benefits are 
obtained $[3,26]$. In the present study, the aerobic exercise training program was intensive, representing approximately $70-80 \%$ of the rats $\mathrm{VO}_{2 \max }$ [27]. The potential ability of RT to improve glycemic control (determined by $\mathrm{HbA}_{1 \mathrm{C}}$ ) in populations with T1DM is inconclusive [28], and the present results would support work citing that it has no benefit on long-term glycemia [29]. There was no improvement in fructosamine levels in D-ART, despite supplementing RT with $\mathrm{AT}_{\text {high }}$, suggesting that the frequency of $\mathrm{AT}_{\text {high }}$ may be an important factor to experience glycemic benefits. However, since food consumption was not directly measured in the current study, it cannot be completely discounted that the diets of experimental groups may not have been isocaloric.

In a previous report, we demonstrated that six weeks of RT provided little protection against an I-R injury in T1DM rats [4]. The current study demonstrated that longer term RT, conducted alone or paired with $\mathrm{AT}_{\text {high }}$ (D-ART), is necessary in order to provide similar levels of cardioprotection as performing strictly $\mathrm{AT}_{\text {high }}$. Indeed, it has been demonstrated in non-T1DM rats that short-term RT provides little cardioprotection [30]; however, if the RT is prolonged, the cardioprotective effects of this form of exercise become evident, as demonstrated by reduced infarct size following an I-R injury [31]. Again, it is of importance to note that we see unique advantages associated with RT that were not evident in other modalities of exercise. The maximal rate of pressure development $(+\mathrm{dp} / \mathrm{dt})$ and relaxation $(-\mathrm{dp} / \mathrm{dt})$ in T1DM rats were significantly improved in experimental groups utilizing $\mathrm{RT}$ that were not evident in $\mathrm{D}-\mathrm{AT}_{\text {high }}$. It has been reported that just a single bout of RT can improve the rate of left ventricular systolic pressure in hypertensive rats undergoing Langendorf perfusion [32]. Further, Melo et al. [33] reported faster cardiomyocyte contraction and relaxation in rats following eight weeks of $\mathrm{RT}$, believed to be due to increased sarcoplasmic reticulum $\mathrm{Ca}^{2+}$-ATPase (SERCA2a) expression. While neither $+\mathrm{dp} / \mathrm{dt}$ nor $-\mathrm{dp} / \mathrm{dt}$ were altered in $\mathrm{D}-\mathrm{AT}_{\text {high }}$, these results may not be surprising as little change in $\mathrm{Ca}^{2+}$ regulatory mechanisms is reported elsewhere in rat hearts following 12 weeks of treadmill training [34]. Thus, these findings may support the incorporation of RT into the treatment of T1DM, since slowed $\mathrm{Ca}^{2+}$ clearing and abnormal cardiomyocyte excitation-contraction coupling are prominent in T1DM [35].

The finding that rates of pressure development and relaxation were increased in D-RT and D-ART despite no improvement in glycemia (fructosamine) indicates that other factors may contribute to changes in rates of pressure development. For example, cardiomyocytes from insulinresistant rats have demonstrated mechanical defects and impaired $\mathrm{Ca}^{2+}$ handling $[36,37]$. In the present investigation, we report a negative correlation between the degree of insulin resistance and the rate of developed pressure. Indeed, the experimental groups that demonstrated the greatest insulin sensitivity, D-RT and D-ART, also displayed the quickest rates of pressure development and relaxation. In the insulinresistant state, impaired SERCA activity is well documented to contribute to cardiomyocyte dysfunction [38], and RT itself has been shown to increase SERCA expression [33].
In the present study, SERCA2 expression was not changed as a result of RT or ART. This lack of change may not reflect changes in the activity levels of this enzyme, as impaired SERCA activity has been reported in insulin-resistant animals despite normal protein content [38]. Nonetheless, the implications of insulin resistance in the recovery from an I-R injury are significant and require further investigation, given the emerging evidence of "double diabetes," a separate classification of patients with T1DM that exhibit both insulin deficiency and resistance [39].

In seeking to explain the mechanistic means by which a specific exercise training regime may prove to be more beneficial for the functional recovery of the heart during an I-R injury, we examined cardiac Hsp70 protein expression in each of the groups $[40,41]$. We observed an increase in left ventricular Hsp70 content in $\mathrm{D}-\mathrm{AT}_{\text {high }}$ compared to both sedentary T1DM groups (D-CIT and D-IIT). Our laboratory, as well as others, has established the importance of exerciseinduced Hsp70 expression in recovery from an I-R injury $[40,41]$. This finding is in line with previous work from our laboratory that demonstrated both short- and longterm aerobic exercise can result in increased Hsp70 in the hearts of insulin-treated T1DM rats [4, 5]. Further, we showed that $\mathrm{D}-\mathrm{AT}_{\text {high }}$ had higher Hsp70 expression than D-RT which supports an earlier finding by our laboratory [4]. While it is not clear why differences in the expression of Hsp70 exist between exercise modalities, it may be reflective of frequency, duration, and/or intensity of the exercise. We have previously shown that antioxidant enzymes are elevated in the myocardium following $\mathrm{AT}_{\text {high }}$, but not following RT [4]. Increases in myocardial antioxidant defenses have been shown to be dependent on the duration and frequency of training [42], while exercise-induced elevations in Hsp70 are known to be intensity-dependent [43]. It is plausible that D-RT did not undergo the same quantity or intensity of exercise as was achieved in $\mathrm{D}-\mathrm{AT}_{\text {high }}$.

The largest barrier to exercise prescription for individuals with T1DM is exercise-induced hypoglycemia [6]. Thus, independent of which exercise provides the largest cardiovascular benefit, the risk of exercise-induced hypoglycemia must also be considered. Similar to past findings [4], D-AT $\mathrm{T}_{\text {high }}$ resulted in a significant drop in blood glucose immediately following exercise, while D-RT did not. Interestingly, the integration of $\mathrm{RT}$ and $\mathrm{AT}_{\text {high }}$ (D-ART) did not alter the abrupt drop in blood glucose in response to $\mathrm{AT}_{\text {high }}$. Recently, our group has demonstrated that both sedentary and aerobically trained T1DM rats using CIT demonstrate hepatic glycogen deficiencies [15], similar to what has been reported using clinical populations [16]. Despite increased glycemic control in IIT, there was no difference in hepatic glycogen content between D-IIT and D-CIT. Further, exercisetrained T1DM rats, regardless of training modality, demonstrated significantly lower liver glycogen content. It is expected that the amount of insulin in circulation in the treatment groups contributed to different hepatic glycogen levels. Both D-CIT and D-IIT had similar exogenous insulin concentrations, which would in turn regulate glycogen storage by increasing the activity of glycogen synthase [44]. 
Moreover, independent of exercise modality, trained T1DM rats displayed the smallest amounts of hepatic glycogen, concurrent with the lowest exogenous insulin requirements. Despite the apparent cardiovascular benefits associated with regular exercise, the decreased hepatic glycogen content in trained T1DM rats could have implications for combatting hypoglycemia, since hepatic glycogen is a prominent source of blood glucose during glucose-demanding states [17, 18]. However, it is important to note that T1DM rats in each of the different training modalities failed to reach hypoglycemic blood glucose concentrations (less than $3 \mathrm{mmol} / \mathrm{L}$ ).

In conclusion, the first objective of the present investigation was to determine if $\mathrm{AT}_{\text {high }}$ coupled with CIT resulted in larger cardioprotective benefits than IIT alone. Findings presented here demonstrate that when CIT was paired with $\mathrm{AT}_{\text {high }}$, the increase in cardioprotection from an I-R injury was similar to that of D-IIT. In fact, the current findings may suggest that CIT with $\mathrm{AT}_{\text {high }}$ may lead to a larger cardiac improvement in T1DM rats than IIT alone, given the potential role of elevated expression of left ventricular Hsp70 with this form of exercise. For the second objective, we determined that following long-term exercise training, both D-ART and D-RT resulted in similar levels of overall cardioprotection as $\mathrm{D}-\mathrm{AT}_{\text {high }}$; although each exercise training modality did appear to provide unique benefits. For example, improved glycemic control was only evident in $\mathrm{D}-\mathrm{AT}_{\text {high }}$, while the largest improvements in insulin sensitivity measures were evident in exercises that utilize resistance exercise (D-ART, $\mathrm{D}-\mathrm{RT}$ ). This study underlines the need to consider other factors besides glycemic control (i.e., insulin resistance) when tailoring an exercise treatment program for the patient with T1DM to reduce the risk of developing CVD.

\section{Data Availability}

The data used to support the findings of this study are available from the corresponding author upon request.

\section{Conflicts of Interest}

The authors declare that they have no conflicts of interest.

\section{Acknowledgments}

This study was supported by Natural Sciences and Engineering Council Discovery Grant (RGPGP-2015-00059).

\section{References}

[1] J. K. Snell-Bergeon and K. Nadeau, "Cardiovascular disease risk in young people with type 1 diabetes," Journal of Cardiovascular Translational Research, vol. 5, no. 4, pp. 446-462, 2012.

[2] D. M. Nathan and for the DCCT/EDIC Research Group, "The diabetes control and complications trial/epidemiology of diabetes interventions and complications study at 30 years: overview," Diabetes Care, vol. 37, no. 1, pp. 9-16, 2014.

[3] M. Chimen, A. Kennedy, K. Nirantharakumar, T. T. Pang, R. Andrews, and P. Narendran, "What are the health benefits of physical activity in type 1 diabetes mellitus? A literature review," Diabetologia, vol. 55, no. 3, pp. 542-551, 2012.

[4] M. W. McDonald, K. E. Hall, M. Jiang, E. G. Noble, and C. W. J. Melling, "Ischemia-reperfusion injury and hypoglycemia risk in insulin-treated T1DM rats following different modalities of regular exercise," Physiological Reports, vol. 2, no. 11, pp. e12201-e12212, 2014.

[5] C. W. J. Melling, K. N. Grisé, C. P. Hasilo et al., “A model of poorly controlled type 1 diabetes mellitus and its treatment with aerobic exercise training," Diabetes \& Metabolism, vol. 39, no. 3, pp. 226-235, 2013.

[6] A.-S. Brazeau, R. Rabasa-Lhoret, I. Strychar, and H. Mircescu, "Barriers to physical activity among patients with type 1 diabetes," Diabetes Care, vol. 31, no. 11, pp. 2108-2109, 2008.

[7] D. P. Zaharieva and M. C. Riddell, "Prevention of exerciseassociated dysglycemia: a case study-based approach," Diabetes Spectrum: A Publication of the American Diabetes Association, vol. 28, no. 1, pp. 55-62, 2015.

[8] Diabetes Control and Complications Trial/Epidemiology of Diabetes Interventions and Complications, L. M. Delahanty, D. M. Nathan et al., "Association of diet with glycated hemoglobin during intensive treatment of type 1 diabetes in the diabetes control and complications trial," The American Journal of Clinical Nutrition, vol. 89, no. 2, pp. 518-524, 2009.

[9] K. N. Grisé, T. D. Olver, M. W. McDonald et al., "High intensity aerobic exercise training improves deficits of cardiovascular autonomic function in a rat model of type 1 diabetes mellitus with moderate hyperglycemia," Journal of Diabetes Research, vol. 2016, Article ID 8164518, 13 pages, 2016.

[10] J. M. Murias, A. Dey, O. A. Campos et al., "High-intensity endurance training results in faster vessel-specific rate of vasorelaxation in type 1 diabetic rats," PLoS One, vol. 8, no. 3, article e59678, 2013.

[11] T. D. Olver, M. W. McDonald, K. N. Grisé et al., "Exercise training enhances insulin-stimulated nerve arterial vasodilation in rats with insulin-treated experimental diabetes," American Journal of Physiology, Regulatory, Integrative and Comparative Physiology, vol. 306, no. 12, pp. R941-R950, 2014.

[12] The Diabetes Control and Complications Trial Research Group, "The effect of intensive treatment of diabetes on the development and progression of long-term complications in insulin-dependent diabetes mellitus," The New England Journal of Medicine, vol. 14, no. 3, pp. 286-287, 1994.

[13] S. J. Cleland, "Cardiovascular risk in double diabetes mellitus-when two worlds collide," Nature Reviews Endocrinology, vol. 8, no. 8, pp. 476-485, 2012.

[14] R. Schechter and S. Reutrakul, "Management of severe insulin resistance in patients with type 1 diabetes," Current Diabetes Reports, vol. 15, no. 10, pp. 77-88, 2015.

[15] M. W. McDonald, M. R. Murray, K. N. Grise et al., "The glucoregulatory response to high-intensity aerobic exercise following training in rats with insulin-treated type 1 diabetes mellitus," Applied Physiology, Nutrition, and Metabolism, vol. 41, no. 6, pp. 631-639, 2016.

[16] M. G. Bischof, M. Krssak, M. Krebs et al., "Effects of shortterm improvement of insulin treatment and glycemia on hepatic glycogen metabolism in type 1 diabetes," Diabetes, vol. 50, no. 2, pp. 392-398, 2001. 
[17] J. Vissing, J. L. Wallace, and H. Galbo, "Effect of liver glycogen content on glucose production in running rats," Journal of Applied Physiology, vol. 66, no. 1, pp. 318-322, 1989.

[18] P. Kishore, I. Gabriely, M. H. Cui et al., "Role of hepatic glycogen breakdown in defective counterregulation of hypoglycemia in intensively treated type 1 diabetes," Diabetes, vol. 55, no. 3, pp. 659-666, 2006.

[19] J. Prestes, R. Leite, G. Pereira et al., "Resistance training and glycogen content in ovariectomized rats," International Journal of Sports Medicine, vol. 33, no. 7, pp. 550-554, 2012.

[20] J. E. Yardley, G. P. Kenny, B. A. Perkins et al., "Resistance versus aerobic exercise acute effects on glycemia in type 1 diabetes," Diabetes Care, vol. 36, no. 3, pp. 537-542, 2013.

[21] M. J. Armstrong and R. J. Sigal, "Physical activity clinical practice guidelines: what's new in 2013?," Canadian Journal of Diabetes, vol. 37, no. 6, pp. 363-366, 2013.

[22] D. A. Sandoval, D. L. A. Guy, M. A. Richardson, A. C. Ertl, and S. N. Davis, "Effects of low and moderate antecedent exercise on counterregulatory responses to subsequent hypoglycemia in type 1 diabetes," Diabetes, vol. 53, no. 7, pp. 1798-1806, 2004.

[23] K. Oppel, L. Bárdos, A. Ferencz et al., "A new, modern, costsaving micro/macro method for the determination of serum fructosamine," Acta Veterinaria Hungarica, vol. 48, no. 3, pp. 285-291, 2000.

[24] K. E. Hall, M. W. McDonald, K. N. Grisé, O. A. Campos, E. G. Noble, and C. W. J. Melling, "The role of resistance and aerobic exercise training on insulin sensitivity measures in STZinduced type 1 diabetic rodents," Metabolism, vol. 62, no. 10, pp. 1485-1494, 2013.

[25] The Diabetes Control and Complications Trial (DCCT)/Epidemiology of Diabetes Interventions and Complications (EDIC) Study Research Group, "Intensive diabetes treatment and cardiovascular outcomes in type 1 diabetes: the DCCT/ EDIC study 30-year follow-up," Diabetes Care, vol. 39, no. 5, pp. 686-693, 2016.

[26] M. A. Salem, M. A. Aboelasrar, N. S. Elbarbary, R. A. Elhilaly, and Y. M. Refaat, "Is exercise a therapeutic tool for improvement of cardiovascular risk factors in adolescents with type 1 diabetes mellitus? A randomised controlled trial," Diabetology and Metabolic Syndrome, vol. 2, no. 1, p. 47, 2010.

[27] T. G. Bedford, C. M. Tipton, N. C. Wilson, R. A. Oppliger, and C. V. Gisolf, "Maximum oxygen consumption of rats and its changes with various experimental procedures," Journal of Applied Physiology, vol. 47, no. 6, pp. 1278-1283, 1979.

[28] J. E. Yardley, R. J. Sigal, B. A. Perkins, M. C. Riddell, and G. P. Kenny, "Resistance exercise in type 1 diabetes," Canadian Journal of Diabetes, vol. 37, no. 6, pp. 420-426, 2013.

[29] A. C. Ramalho, M. de Lourdes Lima, F. Nunes et al., "The effect of resistance versus aerobic training on metabolic control in patients with type-1 diabetes mellitus," Diabetes Research and Clinical Practice, vol. 72, no. 3, pp. 271-276, 2006.

[30] Y. Doustar, F. G. Soufi, A. Jafary, M. M. Saber, and R. Ghiassie, "Role of four-week resistance exercise in preserving the heart against ischaemia-reperfusion-induced injury," Cardiovascular Journal of Africa, vol. 23, no. 8, pp. 451455, 2012.

[31] F. G. Soufi, M. M. Saber, R. Ghiassie, and M. Alipour, "Role of 12-week resistance training in preserving the heart against ischemia-reperfusion-induced injury," Cardiology Journal, vol. 18, no. 2, pp. 140-145, 2011.
[32] A. A. Fernandes, T. O. Faria, R. F. Ribeiro Júnior et al., "A single resistance exercise session improves myocardial contractility in spontaneously hypertensive rats," Brazilian Journal of Medical and Biological Research, vol. 48, no. 9, pp. 813-821, 2015.

[33] S. Melo, V. Barauna, M. Júnior et al., "Resistance training regulates cardiac function through modulation of miRNA-214," International Journal of Molecular Sciences, vol. 16, no. 12, pp. 6855-6867, 2015.

[34] J. Delgado, A. Saborido, M. Morán, and A. Megías, "Chronic and acute exercise do not alter $\mathrm{Ca} 2+$ regulatory systems and ectonucleotidase activities in rat heart," Journal of Applied Physiology, vol. 87, no. 1, pp. 152-160, 1999.

[35] J. Ren and A. J. Davidoff, "Diabetes rapidly induces contractile dysfunctions in isolated ventricular myocytes," American Journal of Physiology-Heart and Circulatory Physiology, vol. 272, no. 1, pp. H148-H158, 1997.

[36] K. Dutta, D. A. Podolin, M. B. Davidson, and A. J. Davidoff, "Cardiomyocyte dysfunction in sucrose-fed rats is associated with insulin resistance," Diabetes, vol. 50, no. 5, pp. $1186-$ 1192, 2001.

[37] M. L. Schwanke, K. Dutta, D. A. Podolin, and A. J. Davidoff, "Cardiomyocyte dysfunction in insulin-resistant rats: a female advantage," Diabetologia, vol. 49, no. 5, pp. 1097-1105, 2006.

[38] L. Wold, K. Dutta, M. Mason et al., "Impaired SERCA function contributes to cardiomyocyte dysfunction in insulin resistant rats," Journal of Molecular and Cellular Cardiology, vol. 39, no. 2, pp. 297-307, 2005.

[39] S. J. Cleland, B. M. Fisher, H. M. Colhoun, N. Sattar, and J. R. Petrie, "Insulin resistance in type 1 diabetes: what is "double diabetes" and what are the risks?," Diabetologia, vol. 56, no. 7, pp. 1462-1470, 2013.

[40] J. J. Hutter, R. Mestril, E. K. W. Tam, R. E. Sievers, W. H. Dillmann, and C. L. Wolfe, "Overexpression of heat shock protein 72 in transgenic mice decreases infarct size in vivo," Circulation, vol. 94, no. 6, pp. 1408-1411, 1996.

[41] Z. Paroo, J. V. Haist, M. Karmazyn, and E. G. Noble, "Exercise improves postischemic cardiac function in males but not females," Circulation Research, vol. 90, no. 8, pp. 911-917, 2002.

[42] S. K. Powers, D. Criswell, J. Lawler et al., "Rigorous exercise training increases superoxide dismutase activity in ventricular myocardium," The American Journal of Physiology, vol. 265, no. 6, pp. H2094-H2098, 1993.

[43] K. J. Milne and E. G. Noble, "Exercise-induced elevation of HSP70 is intensity dependent," Journal of Applied Physiology, vol. 93, no. 2, pp. 561-568, 2002.

[44] A. R. Saltiel and C. R. Kahn, "Insulin signalling and the regulation of glucose and lipid metabolism," Nature, vol. 414, no. 6865, pp. 799-806, 2001. 


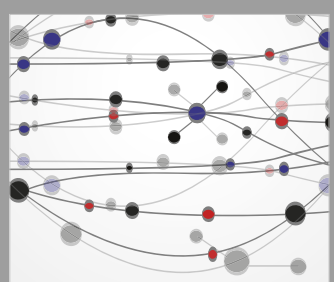

The Scientific World Journal
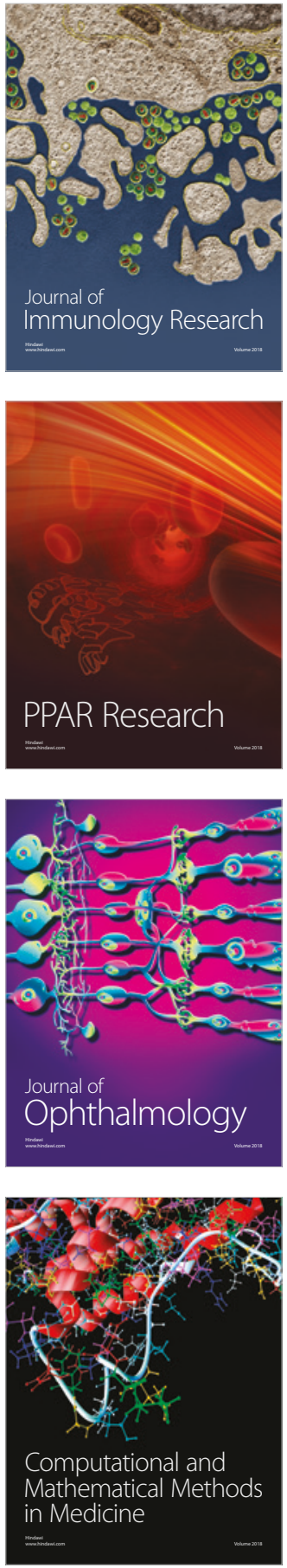

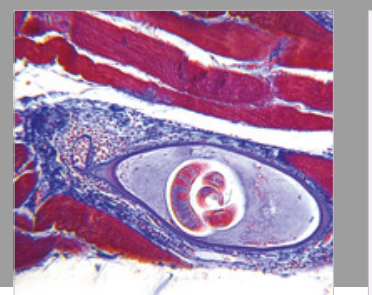

Gastroenterology Research and Practice

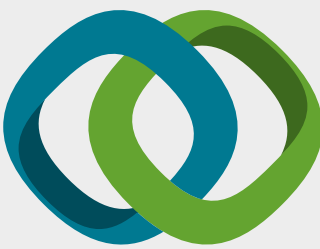

\section{Hindawi}

Submit your manuscripts at

www.hindawi.com
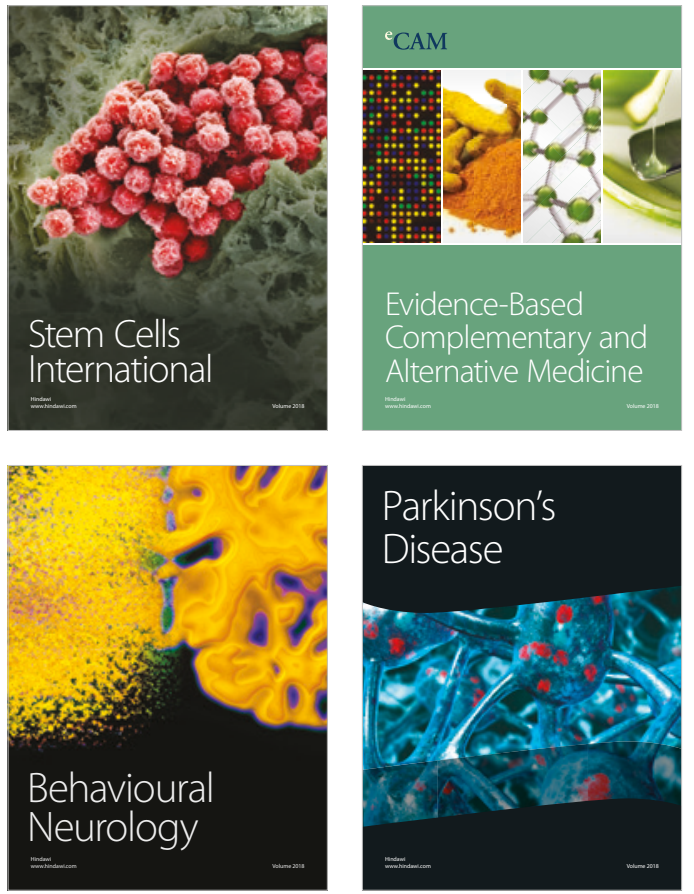

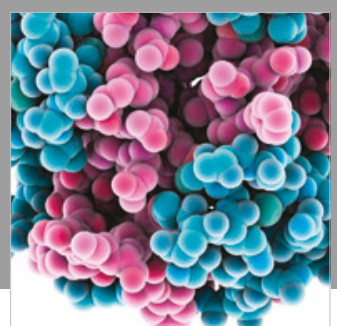

ournal of

Diabetes Research

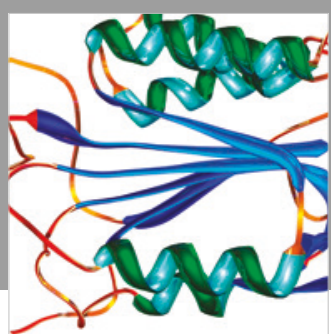

Disease Markers
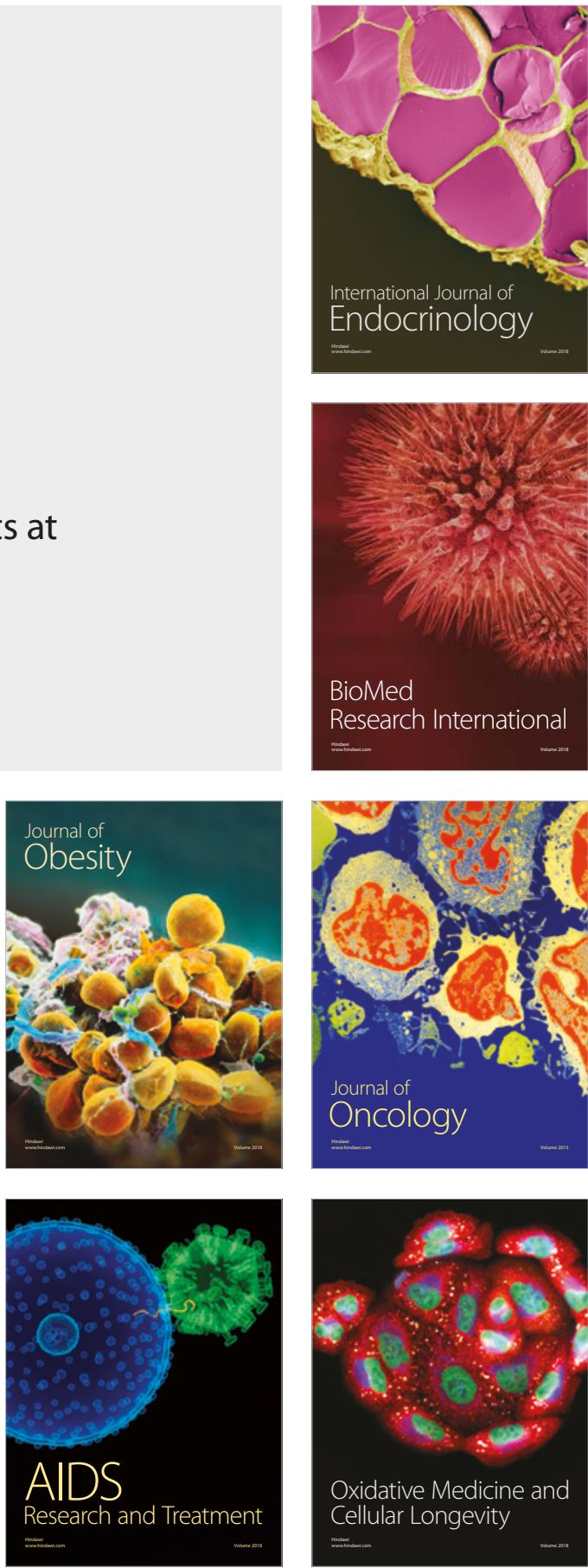